\title{
CAUSES OF VARIATION IN REPRODUCTIVE PERFORMANCE OF WEST AFRICAN DWARF GOAT
}

\author{
*O.A. ADEBAMBO., A.O. SAMUEL AND A.D. ONAKADE \\ Institule of Agric: Research and Training P.M.B. 5029, Ibadan, Nigeria. \\ Received 27 October 1993; accepted 10 March, 1994
}

\begin{abstract}
Analysis was carried out on the reproductive performance of 59 WAD (Foula djallon) goats over 8 year period 1982-1990 under intensive management. The data involving a total of 176 kiddings comprising 311 kids were analysed to provide some information on the reproductive potential and the distribution of the sexes on the WAD goats for an appraisal of its utilization s.. future genetic and environmental studies and the improvement of the breed in Nigeria. The results showed no significant seasonal effect on the kidding pattern. Singles, twins and triplets were $33.44,48.23$ and $16,40 \%$ respectively. Kidding interval varied from 91 to $\therefore$-1! days, annual kidding rate was $1 . .68$ with mean kid birth weight of $1.5 \pm 0 .(18,1.49 \pm 0.65$ and $1.31 \pm 0.095 \mathrm{~kg}$ for single twins and multiple births respectively. The average sex ratio was $48.79 \pm 0.18$. The least squares constants showed that the age of dam, kidding interval and season of kidding have significant effect on the sex ratio with more males born by those after 3 years of age particularly during the dry season If shorter kidding intervals or 191-220 days. Calculated frequency of sex combination of males to females was $0.4005,0.4662$ and 0.1333 trizygotic, dizygotic and monozygotic twins among the triplets - The frequency was 0.67 for monzygotic twinning among the twin births. Although preweaning mortalities of 12.26, 16.33 and $19.36 \%$ were recorded for single, twin and multiple births respectively, highly significant survival rate was recorded in the dry season $(84.40 \pm 0.75)$ than in the wet season $81.18 \pm 0.75$ whilst the kidding interval was between 200 240 days in about $56 \%$ of the population studied. The current emphasis on the presence
\end{abstract}

*Present Address - Dept. of Animal Breeding and Genetics, University of Agriculture, P.M.B. 2240, Abeokuta, Nigeria. of monozygotic twins with a frequency of $67 \%$ among twin birth and $13.3 \%$ among the triplets is to assist in utilizing this trait in the goat for studies that could enhance the modification of the environment or improve the genetic potentials of the breed.

Key words: WAD Goat; Prolificacy, sex ratio, Sex combination, scason, monozygotic twinning.

\section{INTRODUCTION}

Environmental and genetic differences have been associated with differences observed in the reproductive performance of different brecds of the goal (Devendra, 1962; Sacker and Trail, 1966). Although most investigations into goat production show that slightly fewer males than females are born (Epstain, 1953; Sacker and Trail, 1966; Wilkinson and Barbara, 1987) the WAD goats are very prolific, possessing high frequency of kidding and ability to survive under poor management particularly in Nigeria despite their poor genetic potentials for growth and milk production. Their average sizes are small and their weight at birth are often useful prediction of their future performance.

The remarkably high reproductive potential in terms of young produced per female per year (Wilson, 1989; Gall et al 1992) was found to follow the change of dry and rainy seasons and so influenced by temperature, humidity and nutritional status of the animals. The difficulty in identifying with accuracy, ideal materials for twin studics in species other than man and cattle has been one of the problems facing geneticists in the evaluation of genetic and environmental interaction. Hancock (1954), Brumby (1958) and Donald and Watson (1961) reported that twinning studies have been very useful in experiments to determine the effects of different diets, different therapy and any other 


\section{CAUSES OF VARIATION IN REPRODUCTIVE PERFORMANCE OF WAD}

modification of the environment particularly with monozygotic ans. Since hoth members of a pair have the same genotype, by using one as control and the other as the treatment effects any complication from differing genctic susceptibilities such as found in studies involving other relationship is climinated. Investigations have shown that with larger numbers of twins for many kinds of expectations a single monzygotic twin as control is worth some $10-25$ other combinations.

It is important that an appraisal of this herd of goats be made 10 assess their reproductive performance as related to their birth weights, sex ratio and sex combination as possible contributions to any breeding plans. Such information will be uscful in recommending environmental modification for the improvement of the genetic potentials of the breed.

This paper therefore is an attempt to evaluate these parameters and investigate the extent to which performance in this herd could be modified for future breeding programmes.

\section{MATERIALS AND METHODS}

The data consisted of all animals born of the West African dwarl goat (Fouta djallon) at the Institute of Agriculture Research and Training lbadan for nine recording years from 1982 to 1990. The Institules goat herd was established in 1977 from animal purchases made around the South West Zone of Nigeria.

Data collected were those of hirth.weight and sex combination from 176 kiddings comprising 311 kids. Sex ratio was calculated as the number of surviving males to females. Actual and hypothetical frequency of sex combinations were calculated using Allen (1960) procedure. Least squares procedure (Harvey, $1960)$ was used to analyse possible environmental influence on the reproductive performance using the model.

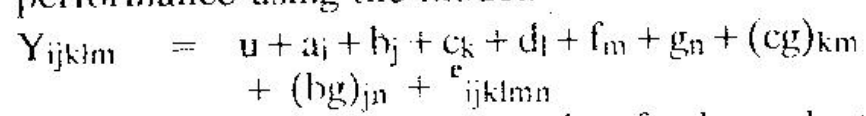

where $Y_{\text {ijkimn }}=$ recourd of dependent variable

$$
u=\text { ma: }: 1 n
$$

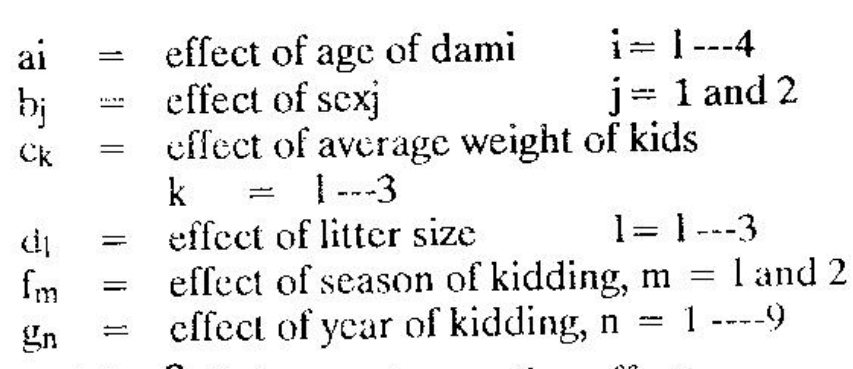

(cg) $\mathrm{kn} \boldsymbol{\&}(\mathrm{bg})_{\mathrm{jn}}=$ interaction effects

Repeatability estimates of birth and kidding rates were calculated using 30 dams with 3 repeated records while heritability estimates were based on daughter dam comparison (Berker, 1975). Ghi-Square was used to test the significance of difference among observed and expected values of the sex ratio and sex combinations. Percentage mortality before weaning over the years and within the types of birth (singles, twins and multiples)was calculatid. The average weights of kids were separatcd for type of birth while the dams ages were calcgorised according to parity. Seasons were classified under the dry period (November to March) and wet jeriod (April to October).

The procedure of Allen (1960) was used to evaluate the proportion of monozygosity among the like sexed twinning in this herd whilst its modification using Weinbergs method (Butmer, 1970) was used to calculate monozygosity amongst the triplets. Thus if $N$ is the total number of twin pairs the proportion of monorygotic twinning $M$ is estimated as

$\mathrm{M}=\{\mathrm{L}-\mathrm{U}\} 100$
$\mathrm{~L}=$ ratio of like-sexed twinning
$\mathrm{U}=$ ratio of unlike sexed twinning
$\mathrm{N}=$ Total number of twin pairs (Allen, 1960)
Using Bulmers (1970) procedure the
frequency of zygosity among triplets was
calculated as follows:

If $\mathrm{M}$ is the rate of monozygotic twinning and $D$ the dizygotic twinning rate, then the frequency of dizygotic triples $\mathrm{T}_{2}$ is $2 \mathrm{MD}$. Half of these are expected to be like-sexed triplets. If the number of unlike-sexed triplets is denoted as $\mathrm{U}$, the number of like-sexed triplet which are not dirygetic will be $U_{-}^{-1} / 2 T_{2}$. This being the value of $3 / 4$ of the trizygotic triplets. Hence the total number of Trizygotic triplets $T_{3}$ is $3 / 4$ 
( $\left.\mathrm{U}_{-} 1 / 2 \mathrm{~T}_{2}\right)$ If $\mathrm{L}$ is the number of like-sexed triplets, the number of monozygotic triplets $T_{1}$ as shown by Allen (1960) becomes $\mathrm{L}+\mathrm{U}-\mathrm{T}_{2}$ $\mathrm{T}_{3}$

\section{RESULTS}

\section{Birth Weights}

The average age at first kidding in this herd was found to be 18.61 months with a range of 15-28 months. The mean birth weight recorded was $1.51 \pm 0.08$ for singles, $1.49 \pm 0.065$ for twinning and $1.31 \pm 0.095$ for multiples. Males were slightly smaller than females with a birth weight of $1.47 \pm 0.008$ and $1.51 \pm 0.003$ respectively (Table1). Heavicr offspring was born during the rainy season $(1.56 \pm 0.07 \mathrm{~kg})$ than during the dry season $(1.44 \pm 0.001 \mathrm{~kg})$. The analysis of variance showed significant differences in birth rate $(\mathbf{P}<0.001)$ within the years and $(\mathbf{P}<0.01)$ within the seasons (Tables 2 \& 3) The mortality records revealed a significant relationship with the birth weight and type of birth. Percentage mortality obtained for singles, twins and multiple births were 12.26, 17.33 and $19.37 \%$ respectively while mean mortality over the years was $15.6 \%$ during the dry season and $18.82 \%$ during the wet season.

\section{Sex Ratio}

The average sex ratio was found to be $\mathbf{4 8 . 7 6}$ \pm 0.18 (Table 3) representing a ratio of $1: 1.07$ which was not significantly different from 1:1 with chi-square of 0.302 at I d.f. hence there was no variation between the observed and expected ratios among the sexes. A significant influence of litter size on sex ratio is indicated from single births to twin births, there is a drop in sex ratio from 49.56 to 48.47 . The sex ratio is a little higher among the triplets and quadruplets. The sex ratio is greatly influenced by the season of kidding $(\mathrm{P}<0.01) \quad($ Table 4$)$ with average sex ratio for kids born in the wet season about 15 units below the sex ratio of kids born in the dry season. Does mated during the dry season are often leaner and in poorer condition at the time of mating than those mated during the rainy season. This may have influence on loss of embryoes. The influence of kidding season on the frequency of multiple births also shows a reduction of litter size for kids born early and later in the year which coincides with the dryer period of the year. Similar variation in the sex ratio and age of dam $(P<0.05)$ and kidding interval were also recorded $(\mathrm{P}<0.01)$.

\section{Sex Combination}

Prolificacy increases with age hence is the ability to produce twins. Proportion of twins and triplets is found to increase from $12 \%$ at first kidding to $54 \%$ in second and subsequent kiddings whilst multiple births increased up to 4 years of age. Out of 176 kiddings in this herd $33.44 \%$ were singles, $48.23 \%$ were twins and $18.32 \%$ were multiples.

A comparison between the actual and hypothetical frequencies of sex combinations (Table 5) may indicate a greater intra uterine death rate for males with increasing litter size. The proportionate increase in the number of monozygotic twinning is expected to increase the proportion of like sexed kids which could be available for nutritional and milk production. studies in different environments. When no monozygotic twinning occurs, the ratio of like sexed to unlike-sexed twins is expected to be 1:1 within the sex ratio of $0.5 .18 .32 \%$ of kids born in this herd were triplets. The equal proportion of like-sexed female triplets to male triplets $(15.78 \%)$ is as would be expected (Table 5) taking the average sex ratio into account and the small sumbers of samples recorded. Using Bulmers (1970) procedure, the frequency of trizygotic triplets was found to be 0:4005 whilst that of di-and monozygotic triplets were $\mathbf{0 . 4 6 6 2}$ and 0.1333 respectively. The proportion of like-sexed triplets was then 0.5652 . Hence out of the 57 kids born as triplets 7.60 are expected to be monozygotic., 26.57 dizygotic and 22.83 trizygotic. Only $4.8 \%$ of all births were recorded as quadruplets.

\section{Heritability}

The Repeatability of birth weight using dams repeated records was $0.128 \pm 0.92$. The heritability of birth weight, sex ratio and sex combination among twins and triplets using the calculated frequency of monozygosity to other 


\section{CAUSES OF VARIATION IN REPRODUCTIVE PERFORMANCE OF WAD}

combination (Table 6) revealed very high genetic variance of $0.14,32.56$ and 42.12 for birth weight, sex ratio and sex combinations respectively relative to $0.092,12.75$ and 18.82 values for the environmental variances. These resulted in heritability estimates of $0.59 \pm 0.45$, $0.72 \pm 0.54$ and $0.69 \pm 0.66$ for these traits. This in essence further confirmed the fact that these traits are highly genetic, coupled with the no interaction effect between these traits over the years (Table 2) it means that the goats' potential for these traits could be further exploited in its future improvement programmes.

\section{DISCUSSION}

Indigenous small ruminants have been reported to have a remarkable reproductive potential in terms of numbers of young produced per female per annum, (Wilson 1989), because day length is relatively constant in the tropical locations. However, reproductive activities do follow the change of dry and rainy season and are influenced by temperature and humidity. Among the small ruminants the WAD goats appear to be the most prolific with more twins and triplets born than singles. Whilst singles were found to vary from $7-10 \%$ among West African Dwarf goats, $25-35 \%$ in Sokoto red goats $32-42 \%$ in the WAD sheep and $50.60 \%$ with Ouda and Yankasa sheep where multiple births could be as low as 1-4\% (Olawale, 1989), it wats much higher in this herd with a value of $33-44 \%$. Prolificacy is found to increase with age hence is the ability to produce twins which tends to increase from first kidding $15-25 \%$ to $60-79 \%$ in second and subsequent kiddings and that mulliple births increased up to 4 years of age (Sacker and Trail, 1966, Kurtze 1981 and Okoroji, 1986).

The prolificacy in this herd, the litter size and age at first kidding compare favourably well with the results of Osuagwuh and Akpokodjc $(1982,1984)$ who reported litter size of $53.29 \%$ for twins and $27 \%$ for triplets. The proportion of multiple births was, however, increasing with the rate of parturition which is bound to ensure high rate of population turnover. The combined effect of multiple birth of $66.6 \%$ is much lower than $80.6 \%$ reported by Osuagwuh and Akpokodje (1984) although higher than 10.15\% twinning incidence reported by Mason and Maule (1960) in East African Dwarf goats and $30 \%$ for Mubende goats in Uganda (Sacker and Trail 1966).

Even though more kiddings occur during the rains (April-October) 58\%, the season of the year had no significant effect on the kidding rate. Similar observation was made in Dwarf goats of Southern Ghana (Devendra and Burns 1970), although a peak of kidding rate was reported around April and another small peak in Scptember in these goats. The lack of interaction between birth weight and the sexes within the years indicated lack of variation in these traits showing that little improvement has occured in this herd for these two traits and that with proper breeding programme and improved system of management, the genetic potential of these goats could be maximized to ensure increased productivity

The significant role that birth weights play in early mortality of the WAD goats (Osuagwuh and Akpokodje 1981, Devendra and Burns 1970) calls for an urgent attention to both genetic and environmental factors to ensure higher birth weight through selective breeding and intensive research on nutritional needs of the WAD goats during gestation.

The age of dam often reveals some of the environmental variances in reproductive rate. The sex ratio increases with the age of dam, the birth weight of the kids and the average litter size. The age effect is significant, similar to results of Skjervold (1979) in sheep. Higher sex ratio is to ensure rapid turn over of males in the population and profitability to the producer, since greater percentage of males are often destincd for local meat production.

The comparison between the actual and hypothetical frequency of sex combinations may indicate a greater intra uterine death rate for males with increasisng litter size. The difference in sex ratio between singles and multiple births relative to their sex combinations may be due to 
an excess of males among embryos and foetuses which are lost. Hennig (1939) showed that mortality of sheep foetuses increases as the number of corpora lutea increases from one to three. Dolling and Nicolson (1967) also found a significant greater loss of embryo in ewes with two active corpora lutea than did ewes with one. The proportion of like-sexed twins which is in the region of $50.67 \%$ is higher than $25 \%$ found in sheep and among human data from Britain, U.S.A. and Italy (Bulmer 1970). The excess of like-sexed females among twins and triplets goes to further confirm a greater differential loss of predominantly male embryos or foetuses in this herd.

Mortality of lambs and kids (Gall et al., 1992) was reported to be very common and could be as high as $40 \%$ of the young, causing great wastage of resources. Similarly high mortality rate of $38.6 \%$ during the first 3 months of birth was reported by Osuagwuh and Akpokodje (1981, 1984). However, this was significantly lower in this herd. Early kidding age of 18.61 months was also in the range of 19.8 months reported by Osuagwuh and Akpokodje (1984) although the kidding interval (191-240 days) was much shorter than $242.33 \pm$ 50.63 days reported in the same study. The high frequency of monozygotic twinning $67.01 \%$ among kids born as twins and $13.33 \%$ among kids born as triplets will be an asset if these could be utilized for genetic studies of the different twins pairs under different environments. Sex ratio and type of birth have been effectively utilized to provide information about the stress effect of the environments. Hence similar studies within this herd are expected to effect better management practice for small ruminant production.

\section{REFERENCES}

ALLEN C. (1960) A differential method for estimation of type frequencies in iriples and quadruplets Annals Hum (ienct. 12:210-224

BECKER W.A. (1975) Manual of quantilative genetics 3rd Edition Washinton State University
DONALD H.P. and J.P. WATSON (1961) Variance of yield and composition of milk within pairs of twin and single born cattle zeit Tierzucht U. Zuchtungs biol. 75:238-248

BRUMBY, P.J. (1958) Monozygotic twins in dairy cattle improvement ABA 26:1-12

BULMER, F.M. (1970) The biology of twinning in man. Clarendon press Oxford 205p

DEVENDRA C. (1962) Upgrading of local goats by, Anglonubian at Federal Experimental Stations serdang. Malaysia Agricultural Journal 43:265-280

DEVENDRA C. and M. BURNS (1970) Goat production in the tropics. Tech Comm. No. 19 Commonwealth Bureau of Animal Breeding and Genetics. Commonwealth Agricultural Bureau XII 184

DOLLING C.H.C. and A.D. NICOLSON (1967) Vital Statistics for an experimental flock of merino sheep IV failure in conception and embryonic loss as causes of failure to lamb. Aust J. Agric Res 18:767-788.

EPSTEIN H. (1953) The dwarf goat of Africa. East African Agric J. 18:123-132

GALL, C.H., C.H. STIER and M. YOUNAN (1992) Small ruminants in developing countries target for biotechnology. Symp of potentials and limitations of Biotech for Livestock Breeding and Production in developing countries. Mariensec Germany 1992 119-130

HANCOCK J. (1954) Monozygotic twins in catte. Advances in Genet 6:114-181

HARVEY W.R. (1960) Least square analysis of data with unequal subclass numbers. USDA ARS 20-0 157 pp

HENNING; W.I., (1939) Prenatal and Post natal sex ratio in sheep J. Agric. Res. 58:565-579

KURTZE, H. (1981) Goat rearing in Africa. Longman London 2nd Edition pp25.

MANSON I.L. and J.P. MAULE (1960) The indigenous Livestock of Eastern and Southerit Africa. Tech. comm. commonwealth Agric. Bureaux XV + $151 \mathrm{pp}+48$ plates

OKO)ROJI M. (1986) Estimation of genetic parameters; hirth weight and multiple births in goats B.Sc report Dept. of Animal 
Science U.I.)

OLAWALE S.I. (1989) Frequency of oxcurence of twins triplets in sheep and goat B.Sc Res Project I.A.R. \& T. Ibadan)

OSUAGWUH A.I.A. and J.U. AKPOKODJE (1981) The West African Dwarf (Fouta djallon) goat I. Cause of early mortality. International Goat and Sheep research 1:303-309.

OSUAGWUH, A.I.A and J.U. AKPOKODJE (1982) The West African Dwarf goat II Reproductive performance. Proc. 3rd Int. Conf. on Goat Prod. and Disease Tucson Arizona U.S.A. pp 368.

OSUAGWUH, A.I.A. and J.U. AKPOKODJE (1984): The reproductive performance of the West African Dwarf goat. Trop Animal Prod. 9:231 - 238
SACKER G.D. and J.C.M. TRAIL (1966) Production characteristics of a herd of East Africa Mubende goats E. Afric Agric Journ 32: $133-136$

SKJERVOLD H. (1979) Causes of variation, sex ratio and sex combination in multiple births in sheep. Livestock Prod. Sci. 6:387-396

WILKINSON J.M. and A.S. BARBARA (1987) Commercial goat production BSAP professional books Grcat Britain. Ist Edition 30-35.

WILSON R.T. (1989) Reproductive Performance of African indigenous small ruminants under various management systems a review. Anim. Prod. Sci. 20:265 286

Table 1 FREQUENCY OF SEX RATIO AND BIRTH WEIGHT IN DIFFERENT YEARS

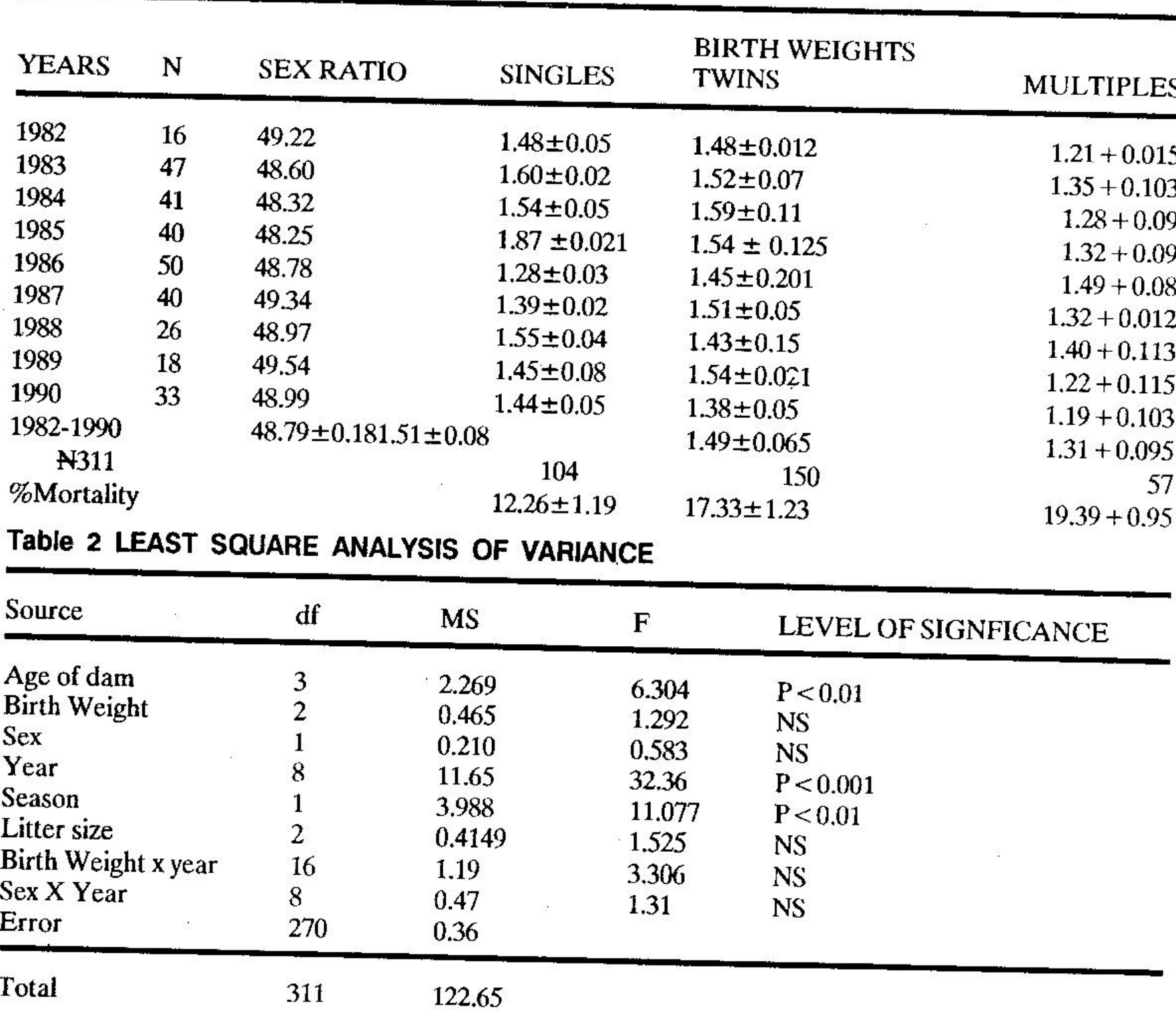


Table 3 MEANS OF BIRTH WEIGHT AS A SIGNIFICANT SOURCE OF VARIATION

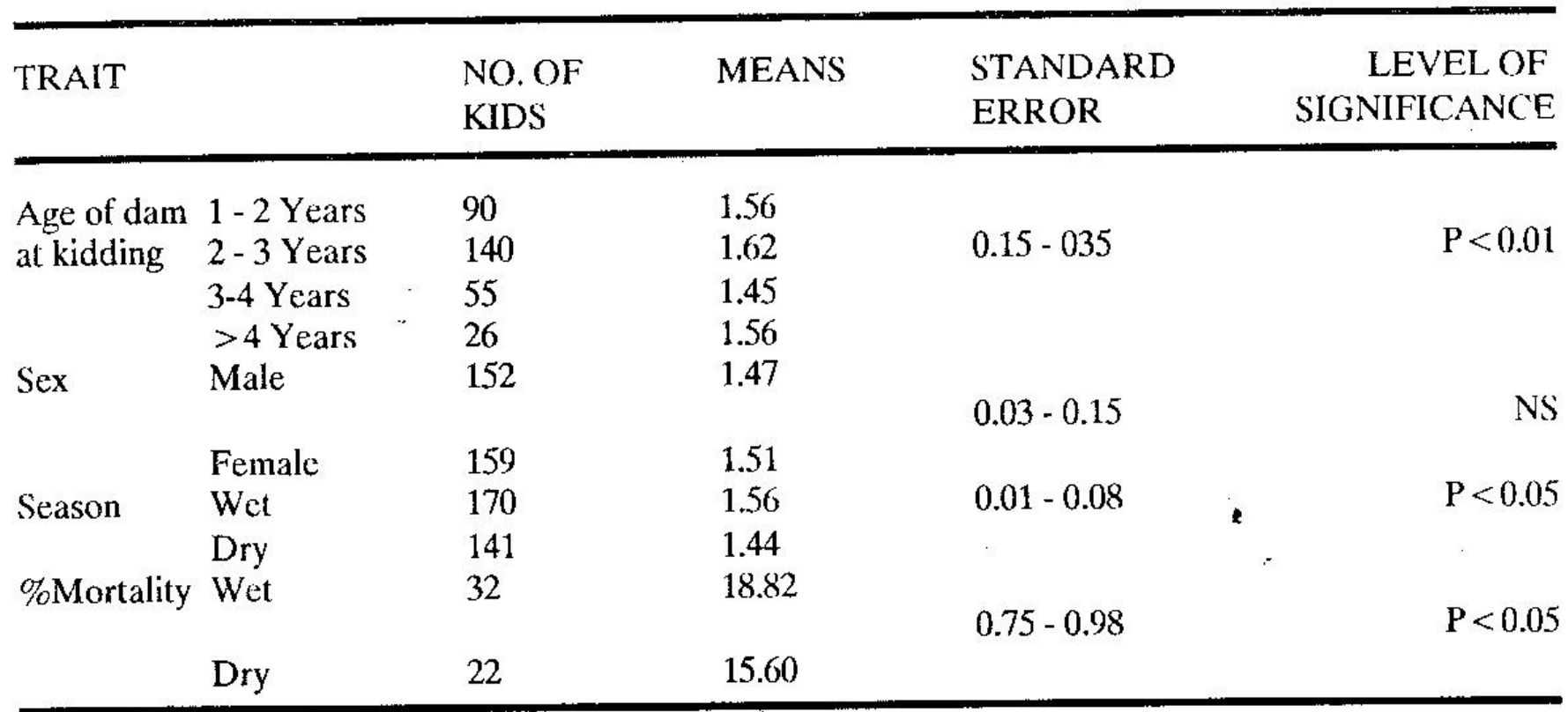

Table 4 CONSTANTS FOR SOURCES OF VARIATION FOR SEX RATIO

NO. OF SEX RATIO CONSTANTS S.E.

LEVEL OF

SIGNIFICANCE

\begin{tabular}{|c|c|c|c|c|c|c|}
\hline Age of dam & 1 - 2 Year & 90 & 48.21 & -0.64 & $0.16-0.29$ & $P<.05$ \\
\hline \multirow[t]{3}{*}{ at kidding } & 2-3 years & 140 & 48.71 & -0.90 & & \\
\hline & 3-4 Year: & 55 & 49.54 & -0.101 & & \\
\hline & $>4$ Years & 26 & 49.41 & 0.63 & & \\
\hline \multirow[t]{3}{*}{ Litter size } & Singles & 104 & 49.56 & -0.32 & & \\
\hline & Twins & 150 & 48.67 & -0.20 & $0.15-0.36$ & NS \\
\hline & Triplets & 57 & 49.12 & -0.13 & & \\
\hline \multirow[t]{2}{*}{ Season } & Dry & 141 & 49.45 & 0.20 & & \\
\hline & Wet & 170 & 48.30 & -0.22 & $0.25-0.35$ & $P<0.01$ \\
\hline Kidding & $191-200$ days & 5 dams & 49.81 & -0.22 & & \\
\hline \multirow[t]{3}{*}{ Interval } & 201-220 days & 17 dams & 49.25 & 0.33 & $0.17-0.24$ & $\mathrm{P}<0.01$ \\
\hline & $221-240$ days & 16 dams & $\$ 48.61$ & 0.46 & & \\
\hline & 240 days & 21 dams & 548.92 & 0.07 & & \\
\hline
\end{tabular}


Table 5 FREQUENCY OF SEX COMBINATION AMONG TWINS AND TRIPLETS

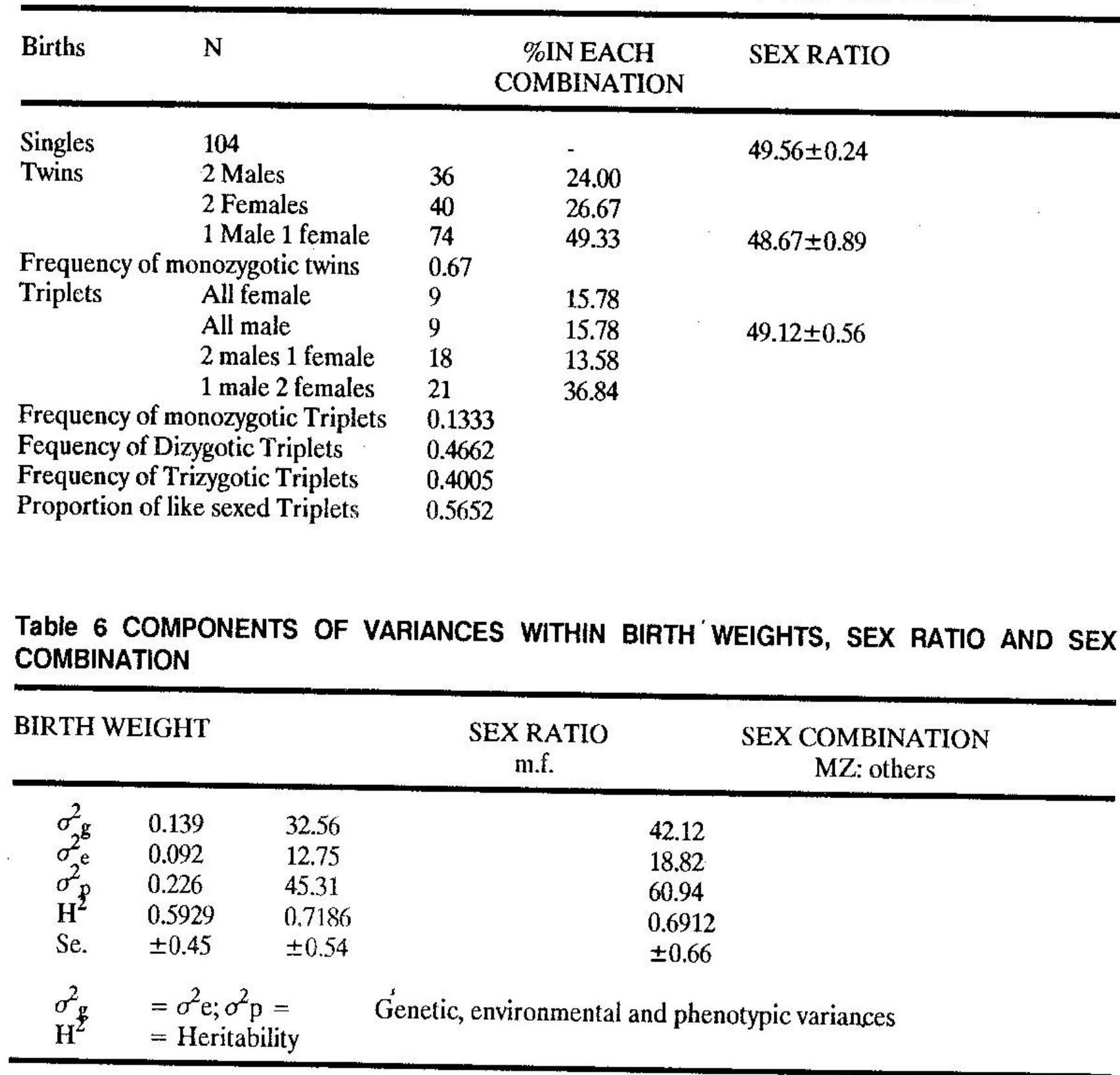

